\title{
Expression and prognostic value of L1-CAM in breast cancer
}

\author{
CHRISTINE SCHRÖDER ${ }^{1,2}$, UDO SCHUMACHER ${ }^{2}$, MINA FOGEL ${ }^{3}$, FRIEDRICH FEUERHAKE ${ }^{4}$, \\ VOLKMAR MÜLLER ${ }^{1}$, RALPH M. WIRTZ ${ }^{5}$, PETER ALTEVOGT ${ }^{6}$, SYLKE KRENKEL ${ }^{1}$, \\ FRITZ JÄNICKE ${ }^{1}$ and KARIN MILDE-LANGOSCH ${ }^{1}$
}

\author{
Departments of ${ }^{1}$ Gynecology and ${ }^{2}$ Anatomy, University Medical Center Hamburg-Eppendorf, Germany; ${ }^{3}$ Department \\ of Pathology, Kaplan Hospital, Rehovot, Israel; ${ }^{4}$ Department of Neuropathology, University of Freiburg; \\ ${ }^{5}$ Siemens Healthcare Diagnostics Products $\mathrm{GmbH}$, Cologne; ${ }^{6}$ Tumor Immunology Programme, \\ D015 German Cancer Research Center, Heidelberg, Germany
}

Received June 15, 2009; Accepted July 20, 2009

DOI: 10.3892/or_00000543

\begin{abstract}
The L1 adhesion molecule (L1-CAM) is associated with impaired prognosis in many carcinomas. However, limited information about its expression in breast cancer tissue is available. Therefore, we carried out an analysis on L1 expression in primary breast cancers using a combination of Western blot, DNA-microarray analysis and immunohistochemistry. We observed L1 protein and mRNA overexpression in $14-15 \%$ of the carcinomas and this was confirmed by immunohistochemical staining. High L1 expression was associated with nodal involvement, high grading, human epidermal growth receptor 2 (Her-2), plasminogen activator inhibitor 1 (PAI-1) and vascular endothelial growth factor (VEGF) expression and a negative estrogen receptor (ER) status, but not with neuroendocrine markers. Moreover, patients with tumors showing high L1-CAM expression had a shorter disease-free and overall survival. Given the emerging functional role of L1 in promoting tumor cell migration, invasion, tumor growth and metastasis, our results suggest that L1 may have this function in breast cancer as well.
\end{abstract}

\section{Introduction}

Breast cancer is the most common cancer in women; worldwide more than one million women will be diagnosed with breast cancer annually (1). While primary breast cancer can be surgically removed, the process of metastasis formation represents a formidable clinical problem as metastasised breast cancer can ultimately not be cured. In order to achieve any progress in the treatment of breast cancer, the molecular

Correspondence to: Dr Karin Milde-Langosch, Department of Gynecology, University Medical Center Hamburg-Eppendorf, Martinistr. 52, D-20246 Hamburg, Germany

E-mail: milde@uke.uni-hamburg.de

Key words: L1-CAM, microarray analysis, Western blots, immunohistochemistry, cell adhesion molecule, prognosis features of metastasis formation have to be understood in order to develop rational treatment strategies.

During malignant progression, cell to cell and cell to matrix interactions mediated by cell adhesion molecules play an important role. Modifications in cell adhesion molecule expression and/or function have been involved in the development of miscellaneous tumor types. Studies have shown, that the dysregulation of cell-cell adhesion caused by changes in the levels of immunoglobulin-like CAMs (Ig-CAM) plays an crucial role in the progression of many epithelial tumors (2).

In this study, we focussed on the cell adhesion molecule L1-CAM, which is a $200-$ to $220-\mathrm{kD}$ type I membrane glycoprotein of the immunoglobulin (Ig) superfamily (3). Several studies have shown that L1-CAM plays a pivotal role during the malignant progress of various human tumors (411). Most notably in melanoma and ovarian/endometrial carcinoma but also in colon cancer, L1-CAM expression has been linked to poor prognosis $(5,6,11,12)$. The interaction of L1-CAM with other molecules is complex as it binds both to L1-CAM molecules on other cells (homophilic binding) (13), to RGD-binding integrins (heterophilic binding) $(14,15)$ and/or to various cell surface molecules of other cells as well as components of the extracellular matrix (reviewed in ref. 16).

On the basis of the scarce information on the role of L1CAM in breast cancer in vivo, we decided to evaluate L1CAM expression in breast cancer samples in terms of prognostic impact and correlations with clinical or histological tumor parameters using cDNA arrays and Western blot analysis.

\section{Patients and methods}

Patients. For the retrospective analysis of L1-CAM protein in tumor lysates, we used 106 primary breast cancer tissue samples which had been collected after surgery, snap-frozen and stored in liquid nitrogen. For array-based L1-CAM mRNA detection, samples from 167 patients were analysed, with an overlap of only 20 cases between the cohorts. All patients were treated for breast cancer at the University Medical Center Hamburg-Eppendorf, Germany, Department of Gynecology, between 1991-2002. Patient selection was 
Table I. Cohort characteristics for L1-CAM protein and mRNA expression analysis.

$\begin{array}{cc}\text { L1-CAM protein analysis } & \text { L1-CAM mRNA analysis } \\ \mathrm{n}(\%) & \mathrm{n}(\%)\end{array}$

Age (years)

Mean age (median)

$56.9(57.0)$

Range

Histological type

Ductal

90 (86)

29-85

Lobular

11 (10)

$117 \quad(70)$

Others/unknown

5 (4)

26 (16)

24 (14)

Tumor stage

pT1

24 (23)

38 (23)

pT2

$63(59)$

112 (67)

pT3

3 (3)

$5 \quad(3)$

pT4

8 (8)

8 (5)

Unknown

$8 \quad(8)$

4 (2)

Grading

G1

6 (6)

12 (7)

G2

$56(53)$

65 (39)

G3

44 (42)

84 (50)

Unknown

$0 \quad(0)$

$6 \quad(4)$

Lymph node involvement

Node positive

25 (24)

$47 \quad(28)$

Node negative

75 (71)

118 (71)

Unknown

$6 \quad(6)$

Estrogen receptor status

Positive

76 (72)

117 (70)

Negative

30 (28)

41 (25)

Unknown

$0 \quad(0)$

$9 \quad(5)$

Progesterone receptor status

Positive

83 (78)

99 (59)

Negative

23 (22)

59 (35)

Unknown

$0 \quad(0)$

Therapy (multiple therapies included)

Adjuvant chemotherapy

36 (34)

$104(62)$

Endocrine treatment

$62(58)$

91 (54)

Unknown

$11(10)$

$6 \quad(4)$

Follow-up

Information available

93 (88)

165 (99)

Recurrence

32 (30)

54 (32)

Died of disease (DOD)

25 (24)

41 (25)

Total number

106

167

based upon availability of tumor tissue. The median followup time was 84 months (range 8-169 months). All patients gave written informed consent to access their tissues and review their medical records in accordance with the principles of the declaration of Helsinki after review and approval of the consent form by the local ethics committee (Ethikkommission der Ärztekammer Hamburg). Breast conserving surgery was performed in $53 \%$ of patients, and $47 \%$ were treated by mastectomy. All additional histological and clinical tumor characteristics are summerized in Table I. 
Protein extraction. Tumor cell content in snap-frozen samples exceeded $40 \%$ as shown by H\&E staining of cryocut sections. Tissue samples of ca. $100 \mathrm{mg}$ were cut from the sample and pulverized using a microdismembrator (BraunMelsungen, Melsungen, Germany) for 2x45 sec at $2000 \mathrm{rpm}$. The resulting powder was immediately suspended in icecold sample buffer pcsb1 (50 mM Tris, $\mathrm{pH} \mathrm{6.8;} \mathrm{1 \%} \mathrm{SDS,}$ $10 \%$ sucrose). The suspension was stored at $-80^{\circ} \mathrm{C}$ until use. Protein content was determined by BCA protein assay.

Western blot analysis. Western blots were performed as described (17). Equal amounts of protein $(20 \mu \mathrm{g})$ of each sample were loaded per well. Electrophoresis was performed in a $6 \%$ polyacrylamide separating gel with a $3 \%$ stacking gel, and proteins were transferred to polyvinylidene difluoride (PVDF) membranes (Immobilon P, Millipore, Eschborn, Germany) by semidry blotting. After overnight incubation at $4^{\circ} \mathrm{C}$ in blocking solution, membranes were incubated for $1 \mathrm{~h}$ at room temperature with MAb L1-11A (subclone of UJ127.11). As secondary antibody, peroxidase-conjugated anti-mouseIgG (Santa Cruz, Heidelberg, Germany; 1:2000) was used, which was visualized by chemiluminescence reagents (Super Signal West Pico kit, Pierce, Rockfort, IL) with Hyperfilm ECL films (GE-Healthcare, Freiburg, Germany). As control for comparable exposure of chemiluminescent membranes and as standard for densitometry, proteins from the cell line HeLa $(20 \mu \mathrm{g})$ and the melanoma cell line FEMX-1 (2 and $20 \mu \mathrm{g}$ ) were loaded.

Subsequently, all membranes were further incubated with goat anti-actin antibodies (I-19; 1:10000; Santa Cruz) and peroxidase-conjugated anti-goat-IgG (1:4000; Santa Cruz) to control loading. Band intensities were quantified by densitometry (GS-700 Imaging Densitometer, Bio-Rad, München, Germany). The intensities of the specific L1-CAM bands were calculated as percent intensity of the control sample (FEMX-1).

Immunohistochemistry. Immunohistochemical studies were performed on formalin-fixed tissue sections embedded in paraffin wax. Three-micron sections were deparaffinized with xylene and rehydrated in a series of ethanols. For epitope retrieval, slides were heated in EDTA ( $\mathrm{pH} \mathrm{8.0)}$, in a digital pressure cooker (Decloaking chamber, Biocare Medical) at $120^{\circ} \mathrm{C}$ for $8 \mathrm{~min}$. After they had cooled, the slides were washed in distilled water. L1 expression was analyzed using an automated I6000 Immunostainer (Biogenex, San Ramon, CA), in accordance with the manufacturer's instructions, using L1 mAb clone 14.10 (18) (Signet Laboratory, Dedham, MA) diluted 1:100. Staining was completed using a Super Picture sensitive polymer detection kit (Zymed, San Francisco, CA) in accordance with the manufacturer's instructions. The color reaction product was developed with either aminoethyl carbazole (AEC) or diamino benzidine (DAB) (Zymed kit). All sections were counterstained with hematoxylin. Antibodies to ER (clone 6F11, Novocastra Laboratory, Newcastle, UK) diluted 1:60, Retrieval in EDTA pH 8.0) or Her-2 (clone TAB 250, Zymed Laboratory, San Francisco, CA) and were used as described by the manufacturer.

RNA isolation. Approximately $50 \mu \mathrm{g}$ of frozen breast tumor tissue was crushed in liquid nitrogen. RLT-buffer (Qiagen, Hilden, Germany) was added and the homogenate was centri- fuged through a QIAshredder column (Qiagen). The total RNA was isolated from the eluate by the RNeasy kit (Qiagen) according to the manufacturer's instructions. RNA yield was determined by UV absorbance and RNA quality was assessed by analysis of ribosomal RNA band integrity on an Agilent 2100 Bioanalyzer RNA 6000 LabChip kit (Agilent Technologies, Palo Alto, CA).

Microarray analysis. The Affymetrix (Santa Clara, CA) HGU133A array and GeneChip System ${ }^{\mathrm{TM}}$ was used to quantify the relative transcript abundance in the breast cancer tissues. Starting from $5 \mu \mathrm{g}$ total RNA, labeled cRNA was prepared using the Roche Microarray cDNA Synthesis, Microarray RNA Target Synthesis (T7) and Microarray Target Purification kit, according to the manufacturer's instructions. In the analysis settings, the global scaling procedure was chosen which multiplied the output signal intensities of each array to a mean target intensity of 500. Samples with suboptimal average signal intensities (i.e., scaling factors $>25$ ) or GAPDH $3^{\prime} / 5^{\prime}$ ratios $>5$ were relabeled and rehybridized on new arrays.

Statistical analysis. Correlations between L1-CAM protein or mRNA expression and histological or clinical tumor characteristics were calculated by $\chi^{2}$ tests using SPSS 15.0 software. For prognostic parameters, the following groups were compared: histological grade, G1/G2 vs. G3; staging, pT1 vs. pT2 vs. pT3/pT4; nodal involvement vs. nodalnegative tumors; ER/PR positive cases vs. ER/PR negative tumors; ductal vs. lobular vs. other carcinomas; age <median vs. $>$ median. Pearson correlation was used as a measure of association between variables using the continuous expression values. Kaplan-Meier analysis was also performed using SPSS 15.0 software. OAS was computed from the date of diagnosis to the date of death due to distant metastasis. Survival curves were compared with the logrank test. Univariate as well as multivariate p-values for the respective risk factors in the survival model were obtained by a Cox proportional hazards model as implemented in SPSS. All tests were performed at a significance level of $\mathrm{p}=0.05$. All p-values are two-sided, and no corrections for multiple testing were applied.

\section{Results}

Detection of L1-CAM by Western blot analysis. Western blot analysis of L1-CAM expression in breast cancer tissues resulted in the detection of broad bands ranging from around 220-140 kD due to partial degradation (Fig. 1A). The band intensities varied strongly within the cohort. In relation to the signal obtained from control cell line which was used in a 1:10 dilution for calculation of band intensities (FMEX-1), the mean L1-CAM expression in the carcinomas ranged from 0 to $252 \%$ with a mean expression of $16.2 \%$ and a median of $1.7 \%$ (Fig. 1B). Thus, L1-CAM protein expression values were not normally distributed. In the vast majority of the cases L1-CAM protein expression was undetectable or very low (Fig. 1A).

Correlation of L1-CAM protein expression with clinical and histological parameters and disease outcome. Because of the abnormal distribution of L1-CAM protein expression levels, 

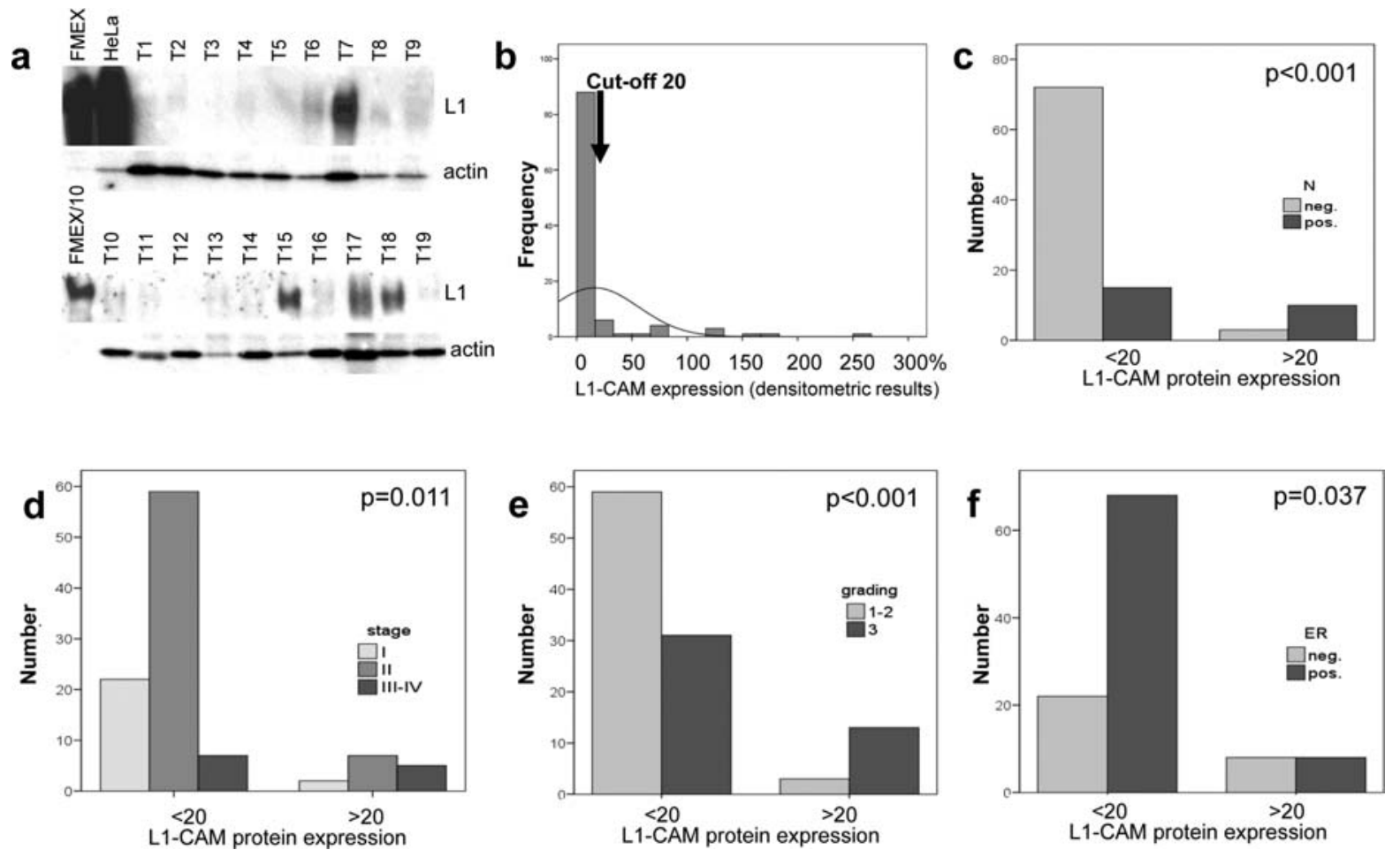

Figure 1. Western blot analysis of L1-CAM expression. (a) Representative Western blot result showing L1-CAM expression in the FMEX melanoma cell line (diluted 1:10 in the lower panel), HeLa cells, and 19 breast cancer samples. As a housekeeping gene, actin detection is shown. (b) Distribution of L1-CAM protein expression values after densitometric evaluation of Western blot results. Expression is given as a percent intensity of a positive control sample ( $2 \mathrm{mg}$ F-MEX cell extracts). For statistical evaluation, a cut-off of $20 \%$ was used (see text). (c-f) Correlations of L1-CAM protein expression levels with clinical stage (c), nodal involvement (d), histological grading (e) and estrogen receptor status (f). Correlations were calculated by $\chi^{2}$ test.

we decided not to use a technical cut-off, i.e. the median, for statistical analysis. Instead, we used a cut-off value of $20 \%$ to generate two groups with absent/low L1-CAM expression $(n=90)$ and L1-CAM overexpression $(n=16)$. By $\chi^{2}$ statistics, we found significant associations of high L1-CAM expression with nodal involvement ( $\mathrm{p}<0.001$; Fig. 1C), high grading $(\mathrm{p}<0.001$; Fig. 1E), advanced clinical stage ( $\mathrm{p}=0.011$; Fig. 1D) and a negative estrogen receptor status ( $\mathrm{p}=0.037$; Fig. 1F). No significant correlations were found with age and progesterone receptor status (data not shown). By Kaplan-Meier analysis, tumors with high L1-CAM expression appeared to have a shorter disease-free survival, but this difference was not statistically significant (data not shown).

L1-CAM detection by immunohistochemistry. In order to find out if the L1-CAM expression detected in Western blots was indeed derived from tumor cells, immunohistochemistry was performed on paraffin sections of 8 tumors, among them 5 cases with strong L1-CAM expression as shown in Western blots. Membraneous and weak cytoplasmic L1-CAM staining in tumor cells was found in 4 cases with L1-CAM overexpression in Western blots (Fig. 2A), with some heterogeneity within the tumors. Within larger tumor cell clusters, the highest staining intensity was detected in marginal tumor cells adjacent to the stroma.

To obtain additional information about the pattern of L1 expression in breast tumors and corresponding metastases, we examined independently 2 other cases of breast carcinoma for which both the primary tumor and the brain metastasis were L1-CAM positive (Fig. 2B). Both the primary tumor and the metastasis were ER negative and Her-2 positive (Fig. 2B) (see also below). Similar results were obtained in the second set of paired tumor samples (data not shown).

L1-CAM RNA detection by microarray analysis. For the analysis of L1-CAM mRNA expression, the datasets obtained on Affymetrix chips using 167 breast cancer samples were used. Since the genchips harbored two probesets for L1CAM (204584_at and 204585_at), we first compared the expression data for both probes by Pearson analysis and found a highly significant positive correlation of both results $(\mathrm{p}<0.001$; data not shown). Since the expression levels for 204584_at were higher than those for 104585_at (mean values 123 and 25, respectively), we decided to use the 204584_at probeset for further analysis. Expression values obtained for this set ranged from 5 to 833.4 (mean 122.6; median 96.5), and similar to the L1-CAM Western blot results, they did not show a normal distribution (Fig. 3A).

Correlation of L1-CAM mRNA expression with established prognostic parameters and disease outcome. For statistical analysis, the 167 patients were first divided into three groups of similar case numbers with low, moderate and high L1CAM mRNA expression levels. Although the third group showed a worse overall survival, this difference was not statistically significant (data not shown). Because of the unnormal distribution of the RNA expression values, we therefore used a cut-off value of 200 that separates a group of 24 tumors (14.5\%) with high L1-CAM RNA expression from the remaining 143 cases $(85.5 \%)$. By comparison of these 


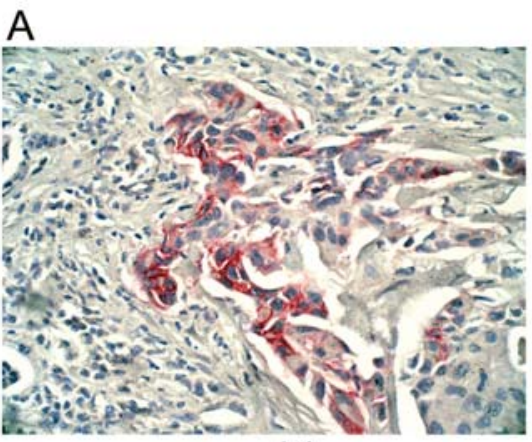

L1

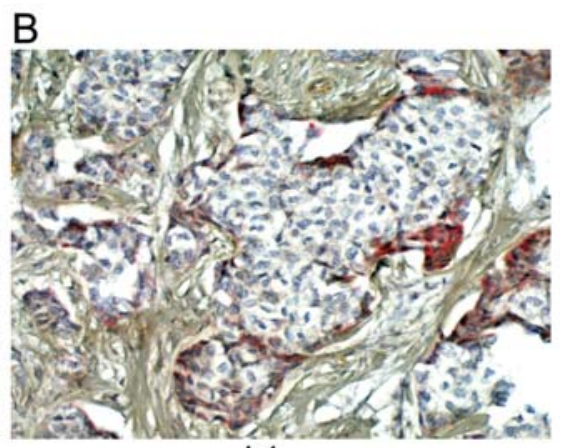

L1

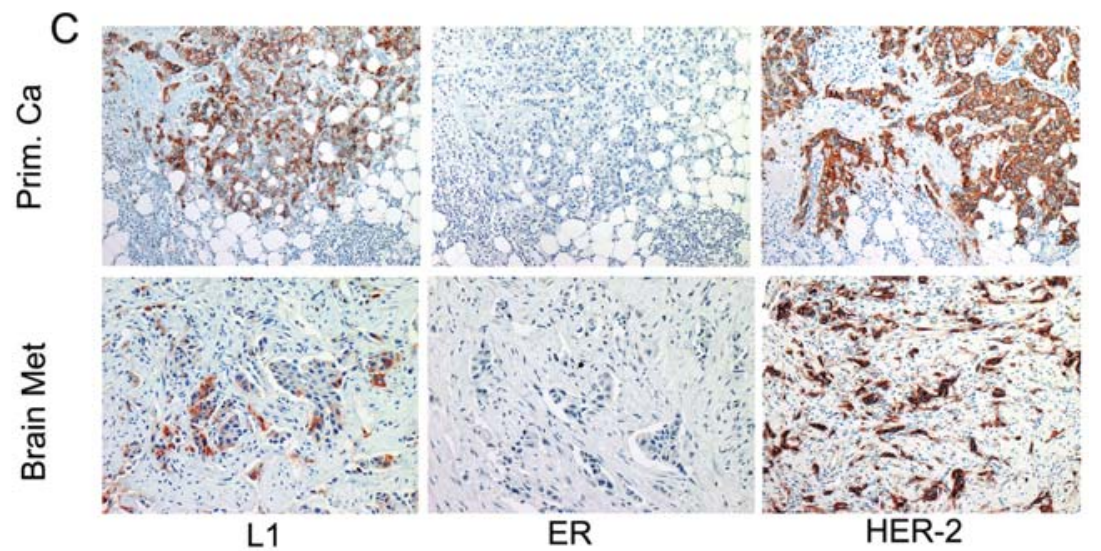

Figure 2. L1-CAM immunohistochemistry showing membraneous and, partially, cytoplasmic staining in tumor cells (x400). (A and B) Representative tumors which had shown strong L1-CAM expression in Western blots. (A) Poorly differentiated ductal carcinoma (stage 2, nodal positive). (B) Moderately differentiated ductal carcinoma (stage 4, nodal positive). (C) Ductal carcinoma and corresponding brain matastasis both showing strong L1-CAM and Her-2 expression but no reactivity for ER.

a

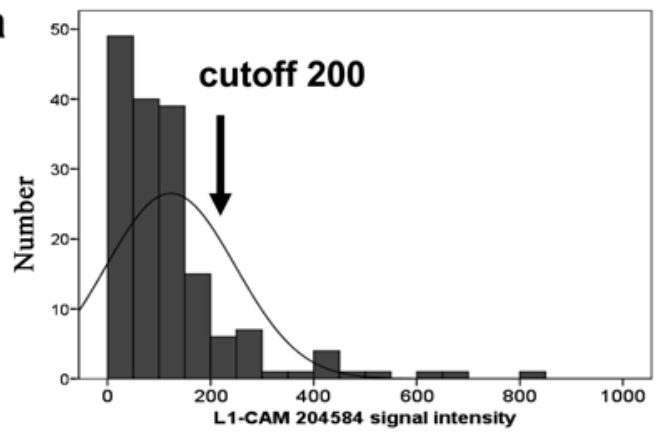

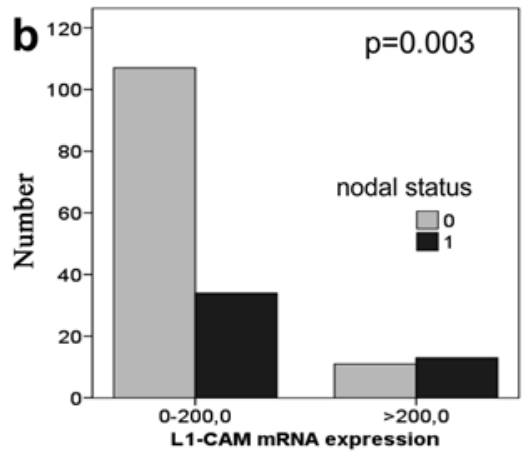
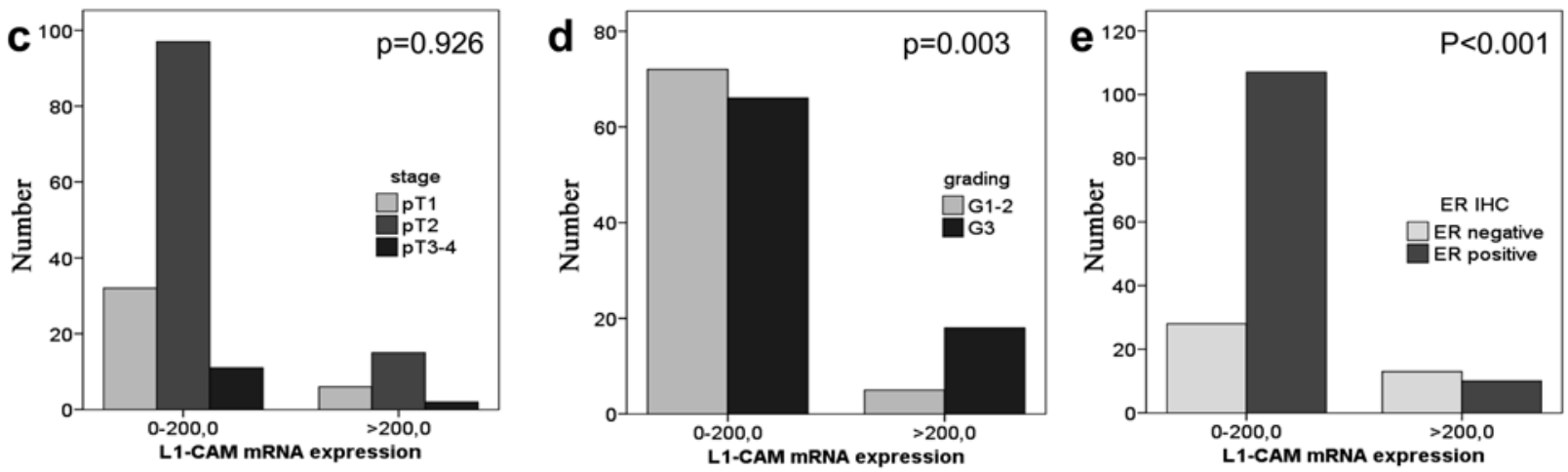

Figure 3. Results of L1-CAM microarray analysis in 167 clinical breast cancer samples. (a) Distribution of L1-CAM mRNA expression data (probeset 204584 at) in 167 breast cancer samples. For statistical evaluation, a cut-off of 200 was used (see arrow). (b-e) Correlations of L1-CAM mRNA expression levels with nodal involvement (b), clinical stage (c), histological grading (d) and estrogen receptor status (e). Correlations were calculated by $\chi^{2}$ test. 
a

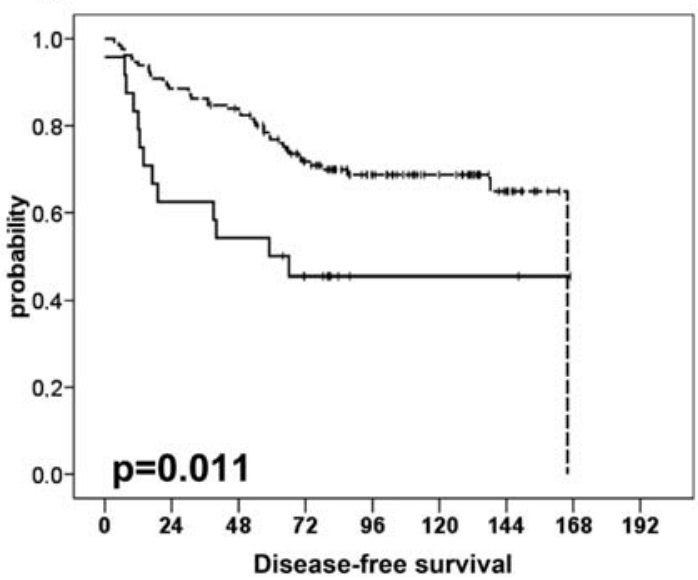

b

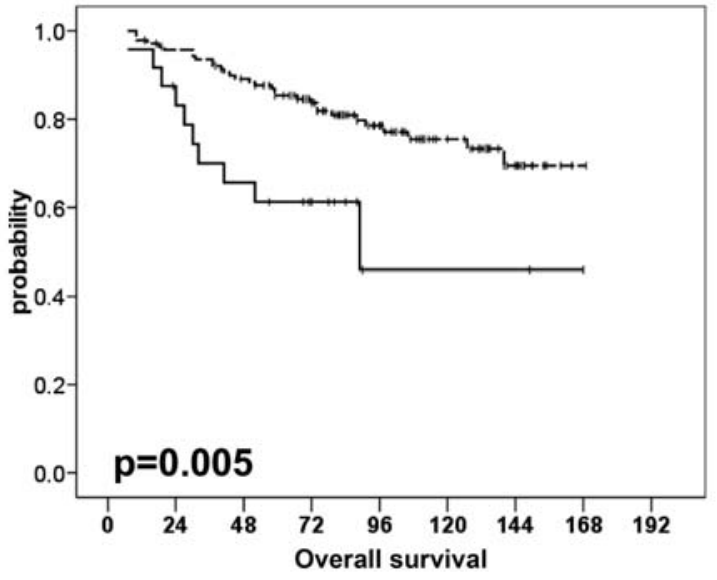

Figure 4. Prognostic impact of L1-CAM mRNA expression in breast cancer patients ( $\mathrm{n}=167)$. The differences in disease-free survival (a) and overall survival (b) in months are shown. Dashed line, low L1-CAM mRNA expression $(<200)$. Solid line, strong L1-CAM mRNA expression ( $>200)$.

groups with respect to clinical and histological parameters, we found significant correlations of L1-CAM expression with nodal involvement ( $\mathrm{p}=0.003$; Fig. 3B), high histological grading $(\mathrm{p}=0.003$; Fig. 3D), a negative estrogen receptor status $(\mathrm{p}<0.001$; Fig. 3E) and progesterone receptor status ( $\mathrm{p}=0.040$; not shown), but no significant association with age ( $\mathrm{p}=0.054$; not shown) and clinical stage ( $\mathrm{p}=0.926$; Fig. 3C). By Kaplan-Meier analysis, patients with high L1-CAM expression levels $(>200)$ had a significantly shorter diseasefree survival $(\mathrm{p}=0.011)$ and overall survival $(\mathrm{p}=0.005)$ than patients with lower L1 mRNA levels (Fig. 4). By multivariate Cox regression analysis including the classical prognostic parameters clinical stage, nodal involvement, histological grading and estrogen receptor status, high L1-CAM expression was a weak independent predictor with borderline significance for a shorter overall survival ( $\mathrm{p}=0.054$; Table II), whereas it lost it prognostic significance for disease-free survival $(\mathrm{p}=0.168)$.

Correlations of MRNA expression levels of L1-CAM and biologically relevant markers. In order to compare the L1CAM expression with other clinically or biologically relevant markers in breast cancer, we correlated mRNA levels of L1-CAM with those of steroid hormone receptors (ER, PR), epidermal growth factor receptor (EGFR), its relative Her2/ erbB2, proteins involved in tumor invasion (uPA, PAI-1, uPAR) and angiogenesis (VEGF-A-C; Table III). By Pearson analysis using the continuous expression values, we could validate the inverse correlation of L1-CAM and ER expression which had been shown on protein level $(\mathrm{p}<0.001)$. Moreover, we found a significant inverse correlation with PR $(\mathrm{p}=0.009)$ and significant direct associations of L1-CAM with HER2 $(p<0.001)$, PAI-1 $(p=0.005)$ and the members of the VEGF family VEGF-A ( $\mathrm{p}=0.014)$, VEGF-B $(\mathrm{p}=0.033)$ and VEGF-C $(\mathrm{p}=0.009)$. In addition, there were non-significant weak associations with EGFR ( $p=0.053)$, uPAR $(p=0.058)$, and uPA expression $(\mathrm{p}=0.101)$. Since the same cohort had been analyzed before with respect of another adhesion protein, the Activated Leukocyte Cell Adhesion Molecule (ALCAM) (19), we also compared the expression levels of both immunoglobulin proteins, but we did not find any significant association $(\mathrm{p}=0.894)$.

L1-CAM is primarily expressed in normal neuronal cells, and in colorectal carcinomas, positive L1-CAM immunostaining correlated with expression of the neuroendocrine marker chromogranin A (18). Therefore, we analyzed mRNA levels of the neuroendocrine markers synaptophysin, chromogranin A, chromogranin B, and neurone-specific enolase, but we did not find any significant association of L1-CAM expression with these markers (Table III).

\section{Discussion}

L1-CAM is known to be expressed by gynecological carcinomas such as ovarian and endometrial cancer but so far no evidence has been provided for its presence in breast carcinoma. In a previous study by Huszar et al 25 cases of infiltrating ductal carcinomas were reported to be L1 negative by immunohistochemical staining (18). In the present study we have reinvestigated primary breast cancers using higher patient numbers and other techniques than IHC to detect L1 in tumor tissues. Positive cases identified using biochemical techniques or microarray analyses were reconfirmed by IHC. Regarding both L1 protein and mRNA expression, we observed a non-normal distribution of expression values, with approximately $15 \%$ of the tumors showing L1 overexpression. In the group of 106 patients where L1 was identified by biochemical means, we observe significant associations of high L1-CAM protein expression with nodal involvement (Fig. 1C), high grading (Fig. 1E), advanced clinical stage (Fig. 1D) and a negative estrogen receptor status (Fig. 1F). By Kaplan-Meier analysis, tumors with high L1-CAM expression appeared to have a shorter disease-free survival, that was, however, not statistically significant. In a second group, 167 tumor-derived mRNAs were investigated by microarray analysis. Subsequent to the analysis these tumors were divided into a high L1-CAM RNA expression group (14.5\%) from the remaining cases with no or little expression $(86.5 \%)$. The comparison of both groups showed again significant correlations of L1-CAM with nodal involvement 
Table II. Cox regression analysis including L1-CAM mRNA expression and conventional prognostic markers (nodal involvement, stage, grading, estrogen receptor status).

\begin{tabular}{|c|c|c|c|}
\hline A. Overall survival & HR & $95 \% \mathrm{CI}$ & P-value \\
\hline \multicolumn{4}{|l|}{ L1-CAM mRNA } \\
\hline$<200$ & 1 & & \\
\hline$\geq 200$ & 2.29 & $0.99-5.29$ & 0.053 \\
\hline \multicolumn{4}{|l|}{ Nodal metastasis } \\
\hline Negative & 1 & & \\
\hline Positive & 1.30 & $0.63-2.66$ & 0.481 \\
\hline \multicolumn{4}{|l|}{ FIGO stage } \\
\hline I-II & 1 & & \\
\hline III-IV & 2.47 & $1.20-5.08$ & 0.014 \\
\hline \multicolumn{4}{|l|}{$\begin{array}{l}\text { Estrogen receptor } \\
\text { status }\end{array}$} \\
\hline Negative & 1 & & \\
\hline Positive & 0.68 & $0.32-1.43$ & 0.306 \\
\hline \multicolumn{4}{|l|}{ Grading } \\
\hline G1-2 & 1 & & \\
\hline G3 & 0.96 & $0.48-1.94$ & 0.911 \\
\hline B. Disease-free survival & HR & $95 \% \mathrm{CI}$ & P-value \\
\hline \multicolumn{4}{|l|}{ L1-CAM mRNA } \\
\hline$<200$ & \multicolumn{2}{|l|}{1} & \\
\hline$\geq 200$ & 1.67 & $0.81-3.47$ & 0.168 \\
\hline \multicolumn{4}{|l|}{ Nodal metastasis } \\
\hline Negative & \multicolumn{2}{|l|}{1} & \\
\hline Positive & 1.73 & $0.95-3.16$ & 0.073 \\
\hline \multicolumn{4}{|l|}{ FIGO stage } \\
\hline I-II & \multicolumn{2}{|l|}{1} & \\
\hline III-IV & 1.29 & $0.70-2.38$ & 0.421 \\
\hline \multicolumn{4}{|l|}{$\begin{array}{l}\text { Estrogen receptor } \\
\text { status }\end{array}$} \\
\hline Negative & \multicolumn{2}{|l|}{1} & \\
\hline Positive & 0.77 & $0.40-1.49$ & 0.434 \\
\hline \multicolumn{4}{|l|}{ Grading } \\
\hline G1-2 & 1 & & \\
\hline G3 & 1.70 & $0.88-3.26$ & 0.114 \\
\hline
\end{tabular}

(Fig. 3B), high histological grading (Fig. 3D), and a negative estrogen receptor status (Fig. 3E). Kaplan-Meier analysis revealed that patients with high L1-CAM expression levels had a significantly shorter disease-free survival and overall survival. Furthermore, high L1-CAM expression was a weak independent predictor with borderline significance for a shorter overall survival (Table II), whereas it lost it prognostic significance for disease-free survival. Thus, both techniques
Table III. Pearson analysis of correlations between mRNA expression levels of L1-CAM and clinically or biologically relevant markers as detected by cDNA array analysis. ${ }^{a}$

\begin{tabular}{lccr}
\hline Gene & $\mathrm{N}$ & $\mathrm{r}$ & P-value \\
\hline Estrogen receptor & 114 & -0.383 & $<\mathbf{0 . 0 0 1}$ \\
Progesterone receptor & 114 & -0.244 & $\mathbf{0 . 0 0 9}$ \\
HER2/ErbB2 & 114 & 0.481 & $<\mathbf{0 . 0 0 1}$ \\
EGFR & 114 & 0.182 & 0.053 \\
uPAR & 114 & 0.178 & 0.101 \\
PAI-1 & 114 & 0.299 & $\mathbf{0 . 0 0 1}$ \\
uPAR & 114 & 0.178 & 0.058 \\
VEGF-A & 114 & 0.230 & $\mathbf{0 . 0 1 4}$ \\
VEGF-B & 114 & 0.199 & $\mathbf{0 . 0 3 3}$ \\
VEGF-C & 114 & 0.245 & $\mathbf{0 . 0 0 9}$ \\
ALCAM & 158 & -0.011 & 0.984 \\
Chromogranin A & 158 & -0.012 & 0.880 \\
Chromogranin B & 158 & 0.016 & 0.840 \\
Synaptophysin & 158 & 0.096 & 0.231 \\
Neurone-specific enolase & 158 & -0.015 & 0.855 \\
\hline
\end{tabular}

${ }^{a}$ Inverse associations are indicated by negative $\mathrm{r}$ values, and significant correlations $(\mathrm{p}<0.050)$ are shown in bold.

of detection of $\mathrm{L} 1$ revealed not only that $\mathrm{L} 1$ was expressed in primary breast tissues but was a marker of poor prognosis for the patients.

We used the data obtained by microarray expression analysis to further examine relevant markers in breast cancer in the L1 positive group. By Pearson analysis we could confirm the inverse correlation of L1-CAM and ER expression and the direct associations of L1-CAM with HER-2, PAI-1 and members of the VEGF family. Interestingly, we observed no association with the neuro-endocrine markers synaptophysin, chromogranin or neurone-specific enolase. The lack of correlation for these markers argues against the assumption that L1 positive tumors are of neuro-endocrine origin which has been observed in L1 positive colon cancers (18). In addition, breast carcinomas with neuro-endocrine differentation defined as being positive for 2-3 markers comprise only approximately $3.3 \%$ of all breast cancers (20).

A major concern of studies based on solubilized tumor tissue is the contribution of normal cells to the detected signal. Although the normal breast is poorly innervated, contaminating nerves could contribute to L1 positivity of the tumor sample. Yet, this would not explain the striking differences in L1 expression between different tumors. We used immmunohistochemical staining to verify that the signals we were detecting were derived from the carcinoma. Indeed, we detected L1 expression in several cases of tumor tissue that had been before identified to have L1 by biochemical means. 
We also detected L1 in two pairs of breast tumor and brain metastasis that had been independently investigated. In these paired samples the tumor and the metastasis were ER negative and Her-2 positive. Although performed only on a few tumors, the phenotype agreed with the observed positive association with Her-2 and negative association with ER found by microarray analysis. In addition, the lack of association of L1 with neural-specific enolase, that is a marker of neural cells, argues against a major contamination of our tumor samples with axons.

Recent investigations on the functional role of L1 in carcinomas have demonstrated that L1 is not only a novel marker but plays an essential role in tumor biology. It was shown that expression of L1 augmented i) cell motility on extracellular matrix components (21-23), ii) enhanced the invasiveness in matrigel assays $(9,24)$, and iii) promoted increased tumor growth in immunodefficient mice $(9,25)$. Importantly, L1 expression can alter gene expression $(23,26,27)$ and is involved in the induction of resistance to chemotherapy $(28,29)$. These findings suggested that L1 in breast tumors could contribute to a more malignant phenotype. Currently, anti-L1 mAb-based immunotherapy is under development with the hope to specifically target L1 positive tumors.

Collectively, our results show for the first time that L1CAM is expressed in a low percentage of human primary breast cancers and marks an aggressive subpopulation. Further studies will be needed to evaluate the role of L1 in metastasis formation.

\section{Acknowledgements}

We thank Renate Gehrke, M. Orlowska-Volk, Tanja Ropers and Elke Veltrup for skillful technical assistance and Brigitte Engelhardt for artwork. This study was supported by grants from the Deutsche Krebshilfe (Schwerpunktprogramm Invasion and Metastasis) to P.A and U.S. and to K.M.-L. (no. 106110).

\section{References}

1. National Cancer Institute: Surveillance epidermiology and end results 2008. http://www.seer.cancer.gov.

2. Cavallaro U and Christofori G: Cell adhesion and signalling by cadherins and Ig-CAMs in cancer. Nat Rev Cancer 4: 118-132, 2004

3. Moos M, Tacke R, Scherer H, Teplow D, Fruh K and Schachner M: Neural adhesion molecule L1 as a member of the immunoglobulin superfamily with binding domains similar to fibronectin. Nature 334: 701-703, 1988.

4. Senner V, Kismann E, Puttmann S, Hoess N, Baur I and Paulus W: L1 expressed by glioma cells promotes adhesion but not migration. Glia 38: 146-154, 2002.

5. Thies A, Schachner M, Moll I, Berger J, Schulze HJ, Brunner G and Schumacher U: Overexpression of the cell adhesion molecule L1 is associated with metastasis in cutaneous malignant melanoma. Eur J Cancer 38: 1708-1716, 2002.

6. Fogel M, Gutwein P, Mechtersheimer S, Riedle S, Stoeck A, Smirnov A, Edler L, Ben AA, Huszar M and Altevogt P: L1 expression as a predictor of progression and survival in patients with uterine and ovarian carcinomas. Lancet 362: 869-875, 2003.

7. Fogel M, Mechtersheimer S, Huszar M, Smirnov A, Abu DA, Tilgen W, Reichrath J, Georg T, Altevogt P and Gutwein P: L1 adhesion molecule (CD 171) in development and progression of human malignant melanoma. Cancer Lett 189: 237-247, 2003
8. Allory Y, Matsuoka Y, Bazille C, Christensen EI, Ronco P and Debiec H: The L1 cell adhesion molecule is induced in renal cancer cells and correlates with metastasis in clear cell carcinomas. Clin Cancer Res 11: 1190-1197, 2005.

9. Gavert N, Conacci-Sorrell M, Gast D, Schneider A, Altevogt P, Brabletz T and Ben-Ze'ev A: L1, a novel target of beta-catenin signaling, transforms cells and is expressed at the invasive front of colon cancers. J Cell Biol 168: 633-642, 2005.

10. Shtutman M, Levina E, Ohouo P, Baig M and Roninson IB: Cell adhesion molecule L1 disrupts E-cadherin-containing adherens junctions and increases scattering and motility of MCF7 breast carcinoma cells. Cancer Res 66: 11370-11380, 2006.

11. Boo YJ, Park JM, Kim J, Chae YS, Min BW, Um JW and Moon HY: L1 expression as a marker for poor prognosis, tumor progression, and short survival in patients with colorectal cancer. Ann Surg Oncol 14: 1703-1711, 2007.

12. Kaifi JT, Reichelt U, Quaas A, Schurr PG, Wachowiak R, Yekebas EF, Strate T, Schneider C, Pantel K, Schachner M, Sauter G and Izbicki JR: L1 is associated with micrometastatic spread and poor outcome in colorectal cancer. Mod Pathol 20: 1183-1190, 2007.

13. Lemmon V, Farr KL and Lagenaur C: L1-mediated axon outgrowth occurs via a homophilic binding mechanism. Neuron 2: 1597-1603, 1989.

14. Ruppert M, Aigner S, Hubbe M, Yagita $\mathrm{H}$ and Altevogt P: The L1 adhesion molecule is a cellular ligand for VLA-5. J Cell Biol 131: 1881-1891, 1995.

15. Felding-Habermann B, Silletti S, Mei F, Siu CH, Yip PM, Brooks PC, Cheresh DA, O'Toole TE, Ginsberg MH and Montgomery AM: A single immunoglobulin-like domain of the human neural cell adhesion molecule L1 supports adhesion by multiple vascular and platelet integrins. J Cell Biol 139: 1567-1581, 1997

16. Brummendorf T, Kenwrick S and Rathjen FG: Neural cell recognition molecule L1: from cell biology to human hereditary brain malformations. Curr Opin Neurobiol 8: 87-97, 1998.

17. Bamberger AM, Methner C, Lisboa BW, Staedtler C, Schulte HM, Loening $\mathrm{T}$ and Milde-Langosch K: Expression pattern of the AP-1 family in breast cancer: association of fosB expression with a well-differentiated, receptor-positive tumor phenotype. Int J Cancer 84: 533-538, 1999.

18. Huszar M, Moldenhauer G, Gschwend V, Ben-Arie A, Altevogt P and Fogel M: Expression profile analysis in multiple human tumors identifies L1 (CD171) as a molecular marker for differential diagnosis and targeted therapy. Hum Pathol 37: 1000-1008, 2006

19. Ihnen M, Mueller V, Wirtz RM, Schroeder C, Krenkel S, Witzel I, Lisboa BW, Jaenicke F and Milde-Langosch K: Predictive impact of activated leukocyte cell adhesion molecule (ALCAM/ CD166) in breast cancer. Breast Cancer Res Treat 112: 419-427, 2008.

20. Makretsov N, Gilks CB, Coldman AJ, Hayes M and Huntsman D: Tissue microarray analysis of neuroendocrine differentiation and its prognostic significance in breast cancer. Hum Pathol 34: 1001-1008, 2003.

21. Mechtersheimer S, Gutwein P, Agmon LN, Stoeck A, Oleszewski M, Riedle S, Postina R, Fahrenholz F, Fogel M, Lemmon V and Altevogt P: Ectodomain shedding of L1 adhesion molecule promotes cell migration by autocrine binding to integrins. J Cell Biol 155: 661-674, 2001.

22. Thelen K, Kedar V, Panicker AK, Schmid RS, Midkiff BR and Maness PF: The neural cell adhesion molecule L1 potentiates integrin-dependent cell migration to extracellular matrix proteins. J Neurosci 22: 4918-4931, 2002.

23. Silletti S, Yebra M, Perez B, Cirulli V, McMahon M and Montgomery AM: Extracellular signal-regulated kinase (ERK)dependent gene expression contributes to L1 cell adhesion molecule-dependent motility and invasion. J Biol Chem 279: 28880-28888, 2004.

24. Meier F, Busch S, Gast D, Goppert A, Altevogt P, Maczey E, Riedle S, Garbe C and Schittek B: The adhesion molecule L1 (CD171) promotes melanoma progression. Int J Cancer 119: 549-555, 2006

25. Gast D, Riedle S, Schabath H, Schlich S, Schneider A, Issa Y, Stoeck A, Fogel M, Joumaa S, Wenger T, Herr I, Gutwein P and Altevogt P: L1 augments cell migration and tumor growth but not beta3 integrin expression in ovarian carcinomas. Int $\mathrm{J}$ Cancer 115: 658-665, 2005. 
26. Gast D, Riedle S, Issa Y, Pfeifer M, Beckhove P, Sanderson MP, Arlt M, Moldenhauer G, Fogel M, Kruger A and Altevogt P: The cytoplasmic part of L1-CAM controls growth and gene expression in human tumors that is reversed by therapeutic antibodies. Oncogene 27: 1281-1289, 2008.

27. Gavert N, Sheffer M, Raveh S, Schneider A, Altevogt P Brabletz T and Ben-Ze'ev A: Expression of L1-CAM and ADAM10 in human colon cancer cells induces metastasis. Cancer Res 67: 7703-7712, 2007.
28. Stoeck A, Gast D, Sanderson MP, Issa Y, Gutwein P and Altevogt P: L1-CAM in a membrane-bound or soluble form augments protection from apoptosis in ovarian carcinoma cells. Gynecol Oncol 104: 461-469, 2007.

29. Sebens Muerkoster S, Werbing V, Sipos B, Debus MA, Witt M, Grossmann M, Leisner D, Kotteritzsch J, Kappes H, Kloppel G, Altevogt P, Folsch UR and Schafer H: Drug-induced expression of the cellular adhesion molecule L1CAM confers anti-apoptotic protection and chemoresistance in pancreatic ductal adenocarcinoma cells. Oncogene 26: 2759-2768, 2007. 